\title{
The Impact of the Andes on Transient Atmospheric Systems: A Comparison between Observations and GCM Results
}

\author{
M. SELUCHI \\ Centro de Investigaciones del Mar y la Atmosfera, CONICET, Buenos Aires, Argentina \\ Y. V. Serafini And H. Le Treut \\ Laboratoire de Meteorologie Dynamique, CNRS, Paris, France
}

(Manuscript received 6 January 1997, in final form 14 August 1997)

\begin{abstract}
The high and low pressure transient systems that cross the Andes at various extratropical latitudes are strongly affected by this natural barrier. Available analysis from operational weather services, such as the European Centre for Medium-Range Weather Forecasts (ECMWF), provide a description of these migrating systems, which are often associated with regional features of orographic origin, such as the Northwestern Argentinean Depression. Their propagation is subject to a particularity: for distinct reasons both low and high pressure systems are commonly deflected to the north when crossing the Andes. The purpose of the paper is to test the ability of an atmospheric general circulation model, the LMD (Laboratoire de Météorologie Dynamique) GCM, to simulate correctly the behavior of these systems. This is done through the analysis of conventional meteorological parameters, but also by duplicating, from the output fields of the model, a series of composite analyses that were previously carried out using both the ECMWF analysis and measurements at local weather stations. The model appears generally successful in reproducing the large-scale features of the circulation. The precipitation patterns are less realistic: they extend too broadly over the eastern side of the mountains, with too little precipitation along the Atlantic coast. Sensitivity experiments are carried out to test the impact of the orography and the role of the model resolution. An experiment with enhanced, and probably more realistic, orography, gives much improved results. An experiment with a lower model resolution shows a degraded but persistent skill in reproducing the observed pattern.
\end{abstract}

\section{Introduction}

The atmospheric flow in the Southern Hemisphere is faced with an obstacle of considerable dimensions, the Andes, which may reach altitudes of more than 6000 $\mathrm{m}$. If we consider the midlatitude regions where the Andes constitute a wall for the westerly winds from the Pacific, the average height is about $5000 \mathrm{~m}$ up to $35^{\circ} \mathrm{S}$, and decreases to altitudes of about $2500 \mathrm{~m}$ southward of $40^{\circ} \mathrm{S}$. Studying the effect of this impressive natural barrier is of course of considerable importance in understanding the climate conditions over South America. It also constitutes an ideal test case for exploring the nature of the synoptic flow in the presence of mountains, and to check the corresponding performance of numerical models. During the last decade the representation of orography within atmospheric general circulation models (GCMs), used for weather forecast or climate sensitivity experiments, has been the subject of many

Corresponding author address: Dr. Hervé Le Treut, Centre National de la Recherche Scientifique, Laboratoire de Météorologie Dynamique, 24, rue Lhomond, 75231 Cedex 05, Paris, France. studies. As model resolution began to increase, the simulations showed an unrealistically intense westerly jet. This was the result of an increase of the simulated baroclinic eddies whose effect was no longer balanced by the unchanged westward drag exerted by mountains. This disruption of a balance between compensating errors set up the way for new parameterizations of the mountain effect: envelope orography or gravity wave drag (Palmer et al. 1986). These schemes were generally tested with the objective of improving the mean meridional circulations and the Northern Hemisphere weather patterns. In the present paper we diagnose the role of orography on the large-scale circulation from a different geographical perspective, and focus our analysis on the characteristics of Southern Hemisphere migratory weather systems.

The migratory systems that cross the Andes are indeed strongly affected by this obstacle, and they are generally deflected northward. This can be understood from basic dynamical and thermodynamical processes. If we model the atmosphere as a slab of air, whose depth is reduced as it crosses the mountains, the conservation of absolute potential vorticity implies a compensating change in relative vorticity. In the Southern Hemisphere, 
where the absolute vorticity is negative, this implies a positive (anticyclonic) perturbation of the relative vorticity, and therefore a northward motion of the weather systems. This well-known feature, however, does not account for all of the orographic effects acting on the flow. Another important effect is the fact that the circulation in the lower atmospheric layers is stopped by the presence of the mountains. The height of the Andes is also not constant, and is larger near $30^{\circ} \mathrm{S}$. A more detailed description of how the transient atmospheric sytems cross the Andes is therefore useful, and the anticyclonic or cyclonic systems need to be considered separately.

In particular, most of the anticyclones are observed behind migrating cold fronts. South of $38^{\circ} \mathrm{S}$, cold air masses can cross the mountains without any difficulty, but farther to the north they are stopped by the Andes and they must cross the mountains more to the south, where their elevation is smaller. This increases the anticyclonic curvature of the migratory systems (Fig. 1a). Once on the eastern part of the Andes, at around $40^{\circ} \mathrm{S}$, the anticyclones are affected again by the orography because the westward flow north of it cannot cross the mountain and is slowed down. As a result, the mountains act as a dam that accumulates the cold air and then increases the anticyclogenesis. Because of this weakening of the westward currents to the north of the systems, there is also a disruption of the geostrophic equilibrium by a corresponding weakening of the Coriolis force, so that the pressure force, directed outward from the pressure center, pushes the anticyclone to the north (Fig. 1a).

A similar feature occurs for cyclonic disturbances, but the reasons are different. If a frontal zone moves over the Andes, the mountains now impede the cold easterlies south of the front from reaching Chile (Fig. $1 b)$. On the western side of the mountain, this lack of cold easterly supply produces a low pressure region that delays the northward front propagation (Lichtenstein 1989). On the eastern side of the mountain, the lee side, subsidence occurs to the north of the front, due to the strong westerlies of baroclinic origin, and ascending motion to the south is caused by a partial ascent of the cold easterlies. This effect contributes to intensify the thermal contrast across the system and a noticeable northward propagation is then produced. The enhanced currents in the middle troposphere, associated with the frontal baroclinicity, therefore act to intensify the thermal orographic depression called Northwestern Argentinean Depression (NWAD) (Lichtenstein 1989). This depression produces ageostrophic circulations, which cause a further frontal acceleration to the north.

The northward deflection of these migratory systems occurs in all seasons. This effect is stronger in winter, however, because the baroclinic regions are then displaced toward regions of higher orography (Phisick 1981).

The objective of this paper is to determine whether (a)

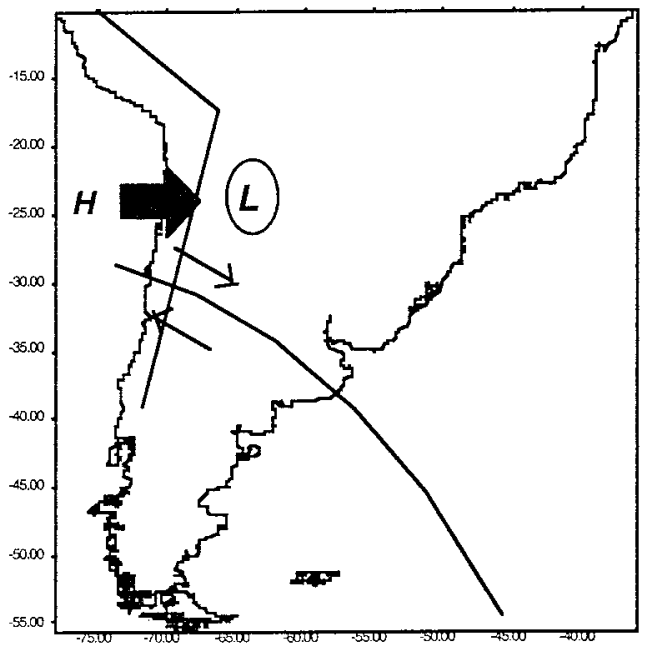

(b)

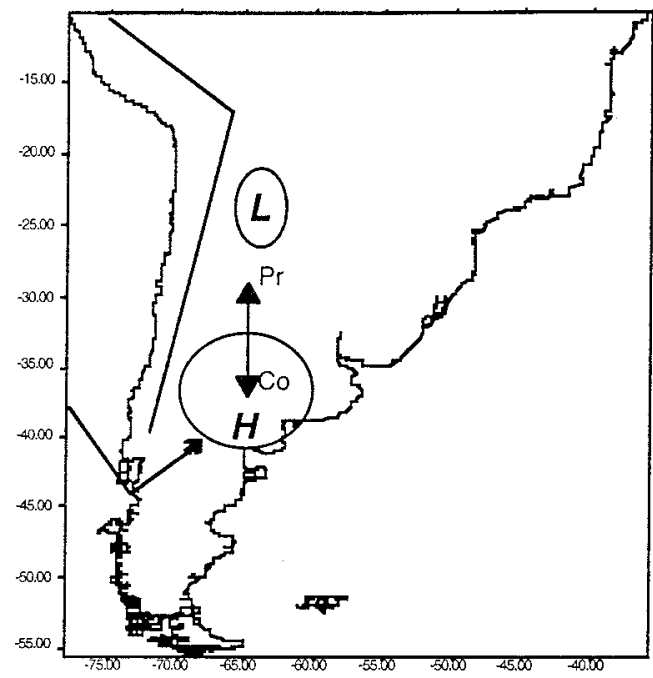

FIG. 1. Transient systems crossing the Andes: a sketch to explain their northward displacement. Two cases are considered: (a) low pressure systems and (b) high pressure systems. In the upper panel the low pressure center north to the front line corresponds to the NADW. The sketch shows the areas of easterlies and westerlies on each side of the front. The cold easterlies are stopped by the mountain and determine a high pressure anomaly on the Chilean side and enhance the NADW (see text for further explanations). In the lower panel the anticyclonic system has crossed the Andes at a southern latitude, and the higher mountains stop the westerlies north of the anticyclone. The simple geostrophic balance shown in the sketch is then disrupted by the diminution of the Coriolis force, which accelerates the anticyclone further to the North.

an atmospheric general circulation model of moderate resolution, as used for climate sensitivity experiments, is able to reproduce those processes that are most important to describing the meteorology over South America. The surface boundary conditions for these atmospheric simulations are the observed sea surface temperatures over the decade from 1979 to 1988, as defined for the Atmospheric Model Intercomparison Program (AMIP). Only the years 1980-84 are used for the analysis, for reasons explained below. In addition, other 
model simulations have been carried out for this shorter period using modified versions of the model to consider the specific role of both the mountain elevation and the effect of model resolution. The model is described in section 2, and a first assessment of its mean performance is given in section 3 by the study of the mean seasonal distribution of sea level pressure (SLP) and precipitation. To validate the model transient behavior, however, a quantitative assessment of the transient circulation features described above is necessary. In our study we use the ECMWF (European Centre for Medium-Range Weather Forecasts) operational analysis, together with data from three local aerological stations. These stations have been chosen to characterize transient systems at different latitudes. They are: Resistencia $\left(27^{\circ} 27^{\prime} \mathrm{S}\right.$, $\left.58^{\circ} 59^{\prime} \mathrm{W}\right)$, Ezeiza $\left(34^{\circ} 49^{\prime} \mathrm{S}, 58^{\circ} 32^{\prime} \mathrm{W}\right)$, and Comodoro Rivadavia $\left(45^{\circ} 47^{\prime} \mathrm{S}, 69^{\circ} 30^{\prime} \mathrm{W}\right)$. The simple methodology to diagnose the transient perturbations was developed by Seluchi (1993) and is described in more detail in section 4 . In section 5 , a few basic statistics about the observed and simulated time series are reviewed. They serve as an a priori validation of the model's ability to adequately describe the observed transient systems. In section 6 the first part of a composite analysis associated with the occurrence of minimum and maximum sea level pressure in the aerological stations is provided. It is completed in section 7 by an analysis of the scatter of the situations entering the composite maps which serves as an a posteriori validation of the method. Finally the propagation of the systems is analyzed in section 8, both from the analysis and the model simulations, for a selected test case.

\section{Model description and design of the experiments}

The first version of the LMD (Laboratoire de Météorologie Dynamique) GCM was described by Sadourny and Laval (1984). Although it has evolved throughout time, some basic features have remained the same. In particular, the dynamical part is written in finite differences using an Arakawa $\mathrm{C}$ grid, a grid that is also chosen to be regular in sine of the latitude and longitude. The model is global and the standard resolution for the experiments described below is 96 points in longitude, 72 points in sine of the latitude, and 15 vertical levels. The standard resolution of the LMD GCM has been lower for a long time: 64 points in longitude, 50 in sine of latitude, and 11 vertical levels. This lower resolution was used for the first official AMIP experiment carried out with the LMD GCM. An experiment at this resolution is considered below under the acronym LR (low resolution).

The version of the model used for the experiments presented in this paper contains a rather comprehensive physical package. It corresponds to the cycle 5.3 of the model, first used and described by Harzallah and Sadourny (1995).
The radiation scheme is the same as used in the ECMWF model: for the solar part it is a refined version of the scheme developed by Fouquart and Bonnel (1980) and the terrestrial component is due to Morcrette (1990). Condensation is parameterized separately for convective and nonconvective clouds and a prognostic equation for cloud water is included (Le Treut et al. 1994). A model for hydrological transfers within different vegetation types, the SECHIBA scheme, is used over land surfaces (Polcher and Laval 1994). The boundary layer is parameterized using a diffusive equation where the mixing coefficient depends on a prescribed length scale and a diagnostic determination of the turbulent kinetic energy. The surface drag parameterization is the one used at ECMWF and includes an explicit dependance of the drag coefficient on the vertical stability of the lower atmospheric layers and the surface wind (Miller et al. 1992). The model also includes a simple representation of the gravity wave drag (Boer et al. 1984)

A feature of the model, which is of importance for the interpretation of the present results, is the treatment of the horizontal dissipation. The model vertical coordinate is the classical sigma coordinate, equal to the pressure normalized by the surface pressure. To avoid unrealistic dynamical effects, however, the horizontal diffusion of the wind divergence and vorticity is computed on isobaric surfaces. This helps to maintain a realistic flow pattern in the presence of mountains, as verified in the Northern Hemisphere by Michaud (1980). But it may also induce adverse effects, such as spurious waves near the surface, when the pressure levels cross the mountains (J. Polcher 1996, personal communication). In the higher resolution of the two model versions considered here, these spurious waves are damped by an increased vertical diffusion. They do not show up in any of the analysis carried out here. This may be due partly to the fact that the composite analysis method selects the most organized part of the flow, and tends to filter out part of the noise. The horizontal diffusion of water vapor is treated differently in the model, by use of an upstream advection scheme, instead of the centered-advection scheme used for the other variables and for the vertical advection of water vapor. The upstream scheme generally conserves the positivity of the water vapor, but is very diffusive. This numerical diffusion occurs over the sigma surfaces, mixes water across the horizontal surfaces, and creates a spurious vertical transport of water vapor. It may be the origin of some of the problems noted below in terms of simulation of precipitation.

The three experiments described in the present paper are the following:

1) A control experiment ( $\mathrm{CO})$, which uses the basic LMD3.5 version of the LMD GCM. The model was run forced by observed SSTs from 1979 to 1989, a choice that corresponds to the period investigated by AMIP, but the period from 1980 to 1984 only was used. Seaice extension was also prescribed in the model. In ad- 
dition to the features already described we can note that in this experiment the orography is averaged over the model grid box. This tends to unrealistically diminish the role of narrow mountain regions, such as the Andes.

2) A first sensitivity experiment is chosen to provide some insight into the role of model resolution. It is referred to as LR (low resolution): the grid on which the dynamics is solved has 64 points in longitude (compared to 96 in the CO case), 50 in sine of the latitude (compared to 72), and 11 vertical levels (compared to 15). This simulation LR also differs from $C O$ and OR because it uses another formulation for the surface drag coefficient, based on the study of Bunker (1989). The implementation of this scheme in our model (Harzallah and Sadourny 1995) leads to rather high values of the surface drag over the oceans, diminishing the velocity of the zonal winds in the lower troposphere, but the drags over the continents are unchanged. We also have made an intermediate experiment, using again the Bunker (1989) drag formulation but at the higher resolution. This experiment is not described here for the sake of clarity, but it ensures that the differences shown below between CO and LR in terms of wave-mountain interaction do primarily reflect the change in resolution between these simulations, and not a change in physical parameterizations.

3) As the grid-box-averaged orography poorly represents the aspect of the Andes, an experiment with enhanced orography has also been carried out for the period 1980-84. This experiment is referred to as OR. The same higher-resolution version of the model is used in the CO and OR simulations, but a 1000-m height increase of the mountains is prescribed in OR. This increased elevation is defined all along the Andes, from the equator to the south. However a smooth transition zone is allowed near the northern and southern limits, so that the increase of $1000 \mathrm{~m}$ is effective in the central part of the Andes only.

\section{Mean performance of the LMD GCM over South America}

The objective of this section is to give a first account of the model's ability to simulate the regional features of the atmospheric circulation over South America, and to estimate its systematic errors before we focus on its performance in terms of transient perturbations.

The maps of the mean sea level pressure (SLP) distribution for the winter season (June, July, August; referred to as JJA) are shown in Fig. 2. They correspond to an average over the years 1980-84, for the three simulations CO, LR, and OR, respectively. In general the correspondence with available climatic in situ observations (Servicio Meteorlógico Nacional 1960; Jenne et al. 1974; Hoffmann 1975; Schwerdtfeger 1976) is rather good. In particular the Pacific anticyclone intersects the continent a few degrees more to the South than the Atlantic anticyclone. This lati-
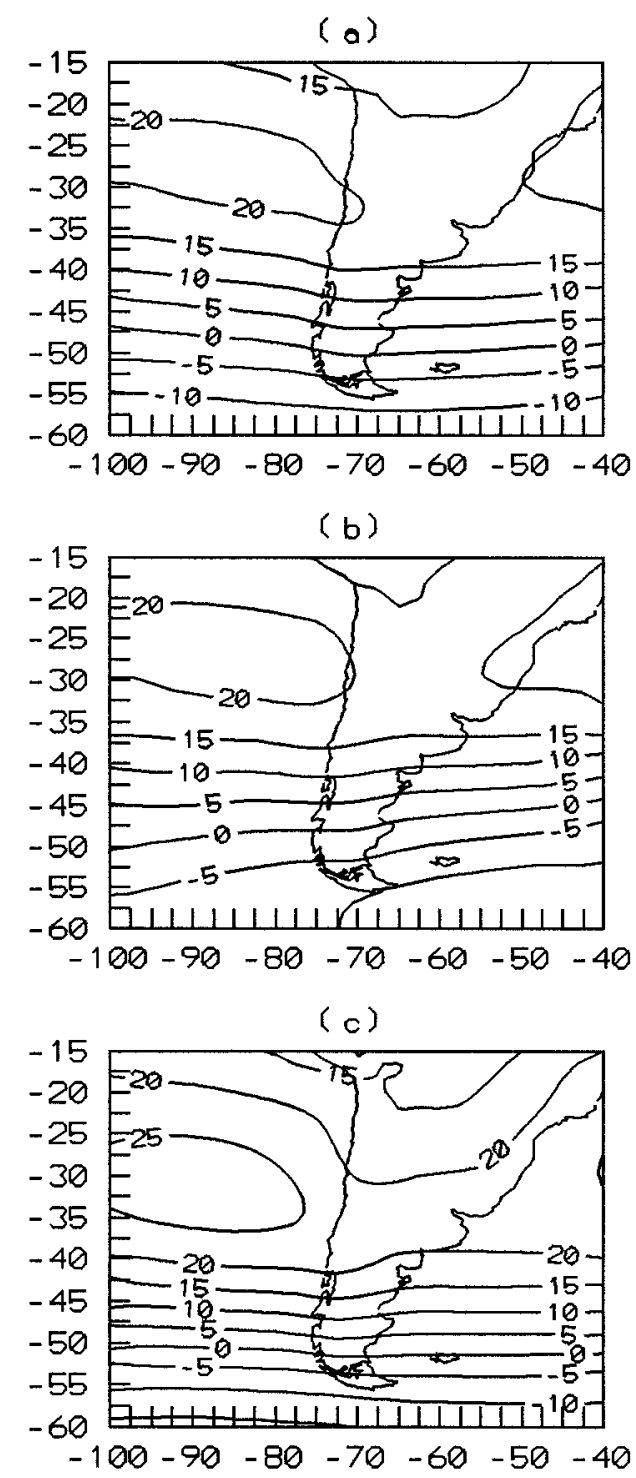

FIG. 2. Mean sea level pressure distribution for the winter (JuneAugust) and for experiments (a) CO, (b) LR, and (c) OR.

tudinal difference appears in all three experiments, but is smaller in the LR simulation (Fig. 2b). In this lowresolution version the flow over the southern extremity of the continent, as shown by the interval between two isolines, appears also slightly too weak. In addition, the depression located at about $60^{\circ} \mathrm{S}$ is not present in the observations. In the two simulations CO and LR, the Pacific anticyclone extends over the South American continent, a feature not present in the observations. The OR simulation, corresponding to the enhanced orography, (Fig. 2c) on the contrary appears more accurate from that and other points of view. Not only is the Pacific anticyclone correctly simulated, but the zone of relatively lower pressures that is found between the two anticyclones, the NWAD, also exhibits a more realistic shape (Lichtenstein 1989). 
The enhanced height of the Andes also induces a better representation of the orographic trough at middlatitudes between $40^{\circ}$ and $50^{\circ} \mathrm{S}$. However the midlatitude zonal flow, which is not shown but can be inferred from the SLP pattern, remains lower than observed. One of the most direct consequences of the presence of the Andes is an important disruption of the zonal flow in the lower troposphere, north of $40^{\circ} \mathrm{S}$. By comparison with Hoffmann (1975), the wind zonal component simulated by the LMD GCM over the Andes is overestimated north of $25^{\circ} \mathrm{S}$. The presence of the Andes, which deflect the atmospheric flow, also induces a strong contrast in meridional wind field on both sides of the mountains. This meridional wind component is shown for the three simulations CO, LR, and OR in Fig. 3. The difference from one side of the mountain to the other is realistically simulated, although with a slightly smaller amplitude than observed (Jenne et al. 1974). The enhanced orography induces again an obvious improvement of the simulations (Fig. 3c). In this simulation, however, the wind speed from the north is underestimated by about $2 \mathrm{~m} \mathrm{~s}^{-1}$ over Brazil, whereas the negative center (wind from the north) at the southwestern part of the continent is about $15^{\circ}$ too far to the north, compared to the observations.

The mean geopotential height (not shown here) in the middle and upper troposphere shows that the differences between the different simulations presented here are smaller in the upper atmosphere than at the surface level. In all cases the model correctly captures observed features: at $850 \mathrm{hPa}$ the larger intensity of the Atlantic anticyclone, compared with the Pacific one, is well reproduced; at 500 and $200 \mathrm{hPa}$, the slight anticyclonic curvature of the flow over South America is also well simulated.

In summer (figures not shown here) the sea level pressure field is characterized by a deeper NWAD, which is intensified by solar radiation. This feature is well captured by all model simulations. The positions of the semipermanent anticyclones is also well reproduced, but their intensity, especially over the Atlantic is more realistic in the OR experiment. The middle-latitude zonal flow in summer is also slightly underestimated in the control simulations, and is again more realistic in the enhanced orography simulation OR.

Another important field to check the quality of a model is the accumulated precipitation, which depends on both physical and dynamical (mainly divergent) processes. Figure 4 presents the precipitation field simulated for winter conditions (JJA) in the three experiments CO, LR, and OR. The differences between the various simulations are slight compared to the difference between any simulation and the observations. The quality of the precipitation field seems to suffer from the limited model resolution much more than the large-scale dynamical features described above do. The climatological maximum of precipitation at middle latitudes is over the Chilean coast (Legates and Wilmott 1990) be-
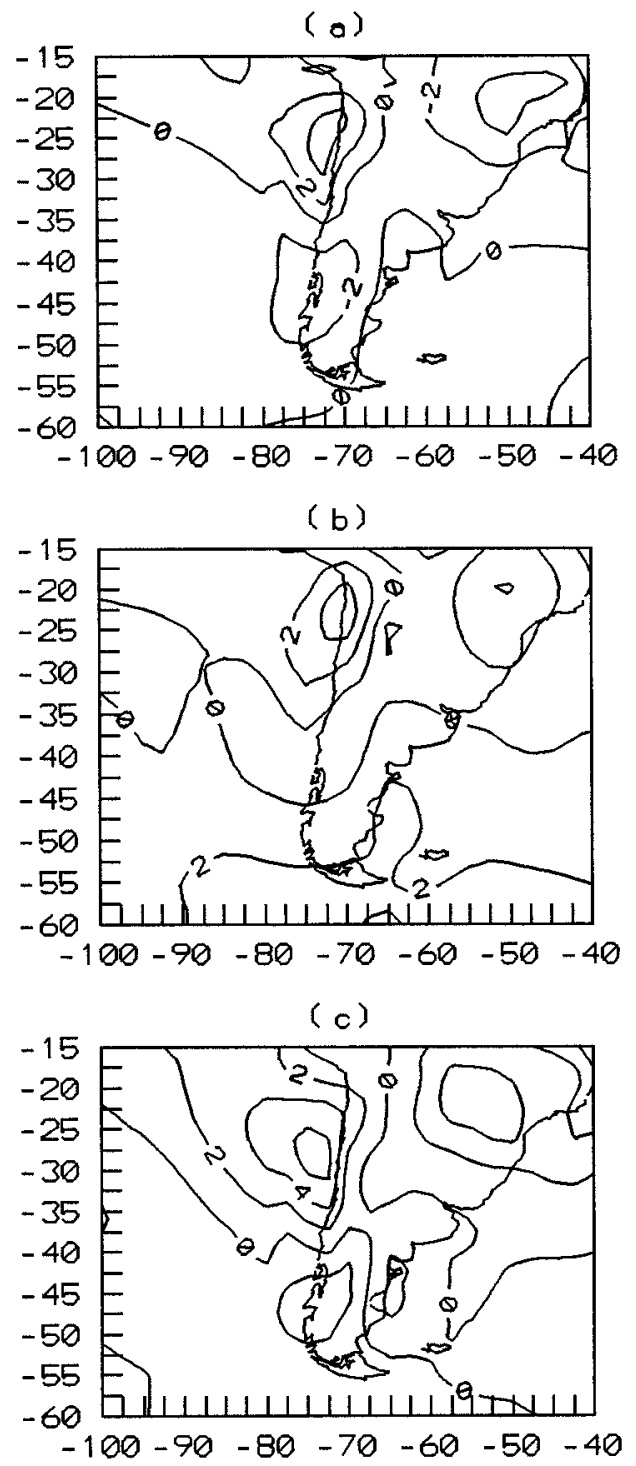

FIG. 3. As for Fig. 2 but for the meridional wind component (m $\mathrm{s}^{-1}$ ). Positive isolines indicate a wind from the south.

cause the westerly systems usually flow against the Andes. These maxima are displaced inland by the model instead of staying west of the mountains, perhaps due to the rather low model resolution, and possibly aggravated by the diffusion problem mentioned above. Despite this improper location, the precipitation amount is correctly simulated. Another deficiency of the LMD GCM is its inability to simulate realistically the contrast in precipitation between the eastern and western parts of the continent. In the real world, a large part of the precipitation over South America is due to water vapor transport from the Atlantic Ocean and the Amazon basin to the continents. It is then transported to the south or southeast by the wind associated with the semipermanent anticyclone and the NWAD. The frontal systems passages, highly frequent up to $25^{\circ} \mathrm{S}$, impede the pen- 


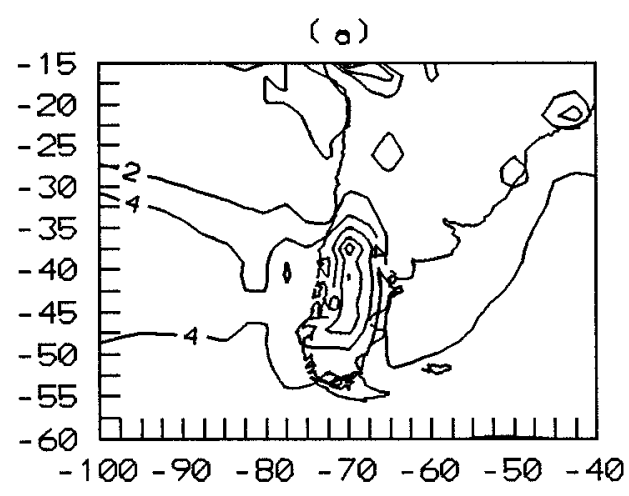

(b)
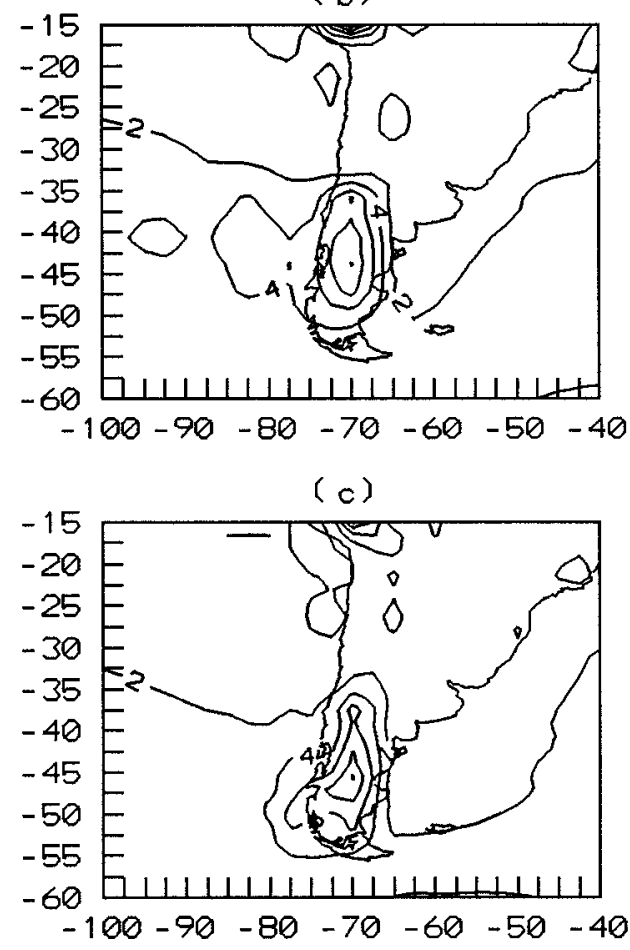

FIG. 4. Distribution of the winter precipitation $\left(\mathrm{mm} \mathrm{day}^{-1}\right)$ for the three simulations (a) CO, (b) LR, and (c) OR

etration of humid air deep into the western part of the continent and the Andes, determining the existence of arid regions. These features are not well reproduced by the model: these arid regions in the central part of the continent are contaminated by the effect of orography. By contrast, precipitation along the Atlantic coast is too weak. In summer the same error affects the precipitation field in the extratropical regions, whereas the maximum of convective origin over the Amazon basin is correctly simulated. The deficiencies in the simulation of the precipitations therefore do not affect primarily convective areas. They also do not reflect any obvious failure in the representation of the large-scale circulation (as will be emphasized later). But they may point to a deficiency in the water transport algorithm of the model, especially in the presence of orography. As mentioned above, the

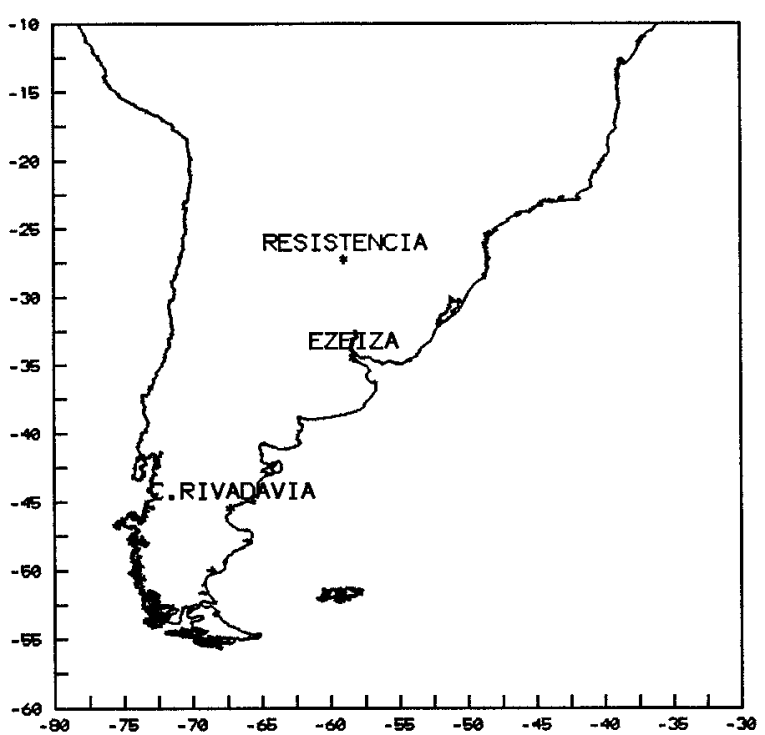

FIG. 5. Location of the aerological stations used in the present study.

diffusive nature of the upstream advection scheme, which creates artificial diffusion of water along sigma surfaces, and hence artificial vertical transport in the mountain areas, may constitute an important source of errors. Another important feature, but more difficult to assess, may be the general tendency of our model to be a few degrees too cold, and consistently too dry, at midtropospheric levels.

\section{Observed data and comparison methodology}

To study the behavior of the transient systems that migrate leeward of the Andes, we rely first on five years of aerological data (1980-84). We have chosen three stations located, respectively, at subtropical, intermediate, and middle latitudes. From north to south they are: Resistencia $\left(27^{\circ} 28^{\prime} \mathrm{S}, 58^{\circ} 59^{\prime} \mathrm{W}\right)$, Ezeiza $\left(34^{\circ} 49^{\prime} \mathrm{S}\right.$, $\left.58^{\circ} 32^{\prime} \mathrm{W}\right)$, and Comodoro Rivadavia $\left(45^{\circ} 47^{\prime} \mathrm{S}\right.$, $69^{\circ} 30^{\prime} \mathrm{W}$ ) (see Fig. 5). They are analyzed jointly with the ECMWF analysis for the years where both types of information were present (1980-84). The choice of this period is in fact governed by both the availability and the condition of the aerological series, which were of a good quality in the early eighties. The accuracy of the ECMWF analysis over South America seems also more highly correlated with the availability and reliability of aerological soundings than with changes in the assimilation methods (W. M. Vargas 1995, personal communication). The original ECMWF analysis for this period is rather low resolution $\left(2.5^{\circ}\right.$, which is slightly better than the model), but its description of extratropical large-scale dynamical perturbations was already fairly accurate, even over South America. These analyses have been available at CIMA (Centro de Investigaciones del Mar y la Atmosfera) and have served as a basis for a 


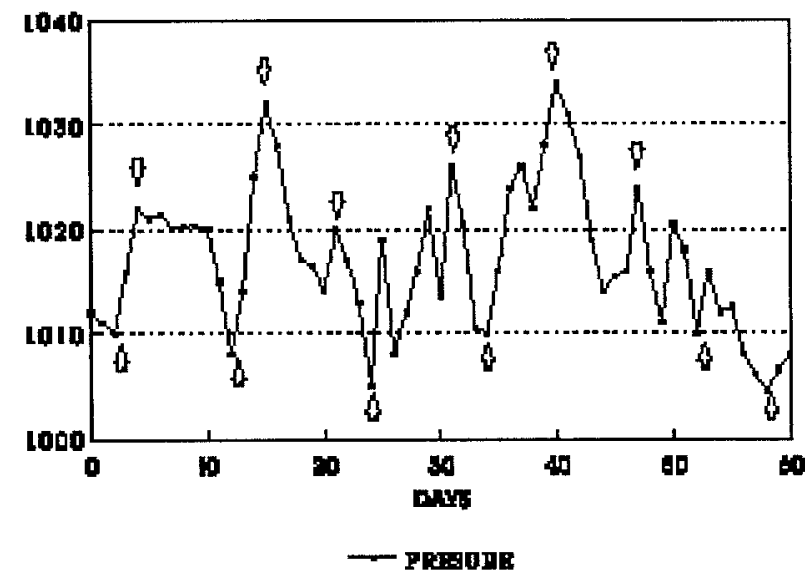

FIG. 6. Example of the cases selected by our procedure, for two months of winter data at the Ezeiza station.

detailed description of the South American migratory systems (Seluchi 1993).

The data analysis is carried out with respect to the three aerological stations, for two seasons, and for both high and low pressure transient systems. In addition to the standard diagnostics (mean, variability) we have tried to get more insight into our results by using a simple composite approach developed by Seluchi (1993) to analyze the dynamical fields. It consists of averaging over the days for which a sea level pressure minimum or maximum is attained at one of the aerological stations. For a given season and a given station, we have three months of data (December, January, and February, or June, July, and August) repeated for five years. The selection of the cases must be done carefully, because the procedure must be robust enough to be repeated with the model results, and because we want to make sure that the selected cases are independent from the other. This means that the amplitude of the perturbation cannot be the only criterium to select the cases. We first reduce the number of selected cases: three minimums and three maximums of the sea level pressure per month. Maxima and minima then have to be separated by at least five days, in order to be considered independent (Madden and Julian 1972) and retained in the analysis. Figure 6 gives an example of a selection procedure over one of the time series under consideration (two months of wintertime pressure data in Ezeiza). We check that our criteria retain a number of cases small enough to be independent, and large enough for the analysis to be significant.

To build a mean history of the perturbation when it crosses the Andes we can also average the fields corresponding to the day(s) before or after the occurrence of the perturbation. If we then subtract from those composite fields the time-averaged mean climatic values, we may diagnose the eastward displacement of the migratory systems, and their northern extension once they have crossed the Andes.
The approach we have followed is attractive because it is conceptually simple, and the risk of mixing processes associated with different physical mechanisms, for example, waves propagating at a different speed, is also easy to identify. A diagnostic of its relevance is to study the variability between the selected cases that enter a composite. This point is addressed in section 7 , after we have examined in section 6 the mean patterns of the various composite fields. It confirms the usefulness of the present methodology.

\section{Basic statistical analysis of the observed and simulated time series}

The first basic analysis proposed in this section is to compare the observed and simulated statistics of the sea level pressure time series in the three aerological stations. Table 1 presents the average value (AVG), the absolute minimum and maximum (MIN, MAX), the variance $\left(S^{2}\right)$, the standard deviation $(S)$, the standard error (SE), the skewness (SK), and the kurtosis $(K)$ of the time series for the three stations for the observations and the three simulations CO, LR, and OR.

The observations show that, when comparing the three stations, the mean sea level pressure is larger in winter in Ezeiza and smaller in Comodoro Rivadavia. The LMD GCM correctly simulates this characteristic, in spite of a tendency to overestimate all pressures, especially in the OR experiment. This effect appears to be systematic and may be due to the fact that the specific altitude of any station may differ from the altitude of the topography averaged over the corresponding model grid box. This in turn affects the interpolation to sea level conditions. It is of course reflected in the maximum and minimum values. But the range of the values (maximum-minimum) is correctly reproduced, with little differences between the simulations.

As may be expected from the locations of the stations, from subtropical to middle latitudes, the dispersion parameters show a clear increase with latitude. The LMD GCM reproduces correctly the daily variability of the pressure time series, since the corresponding statistics are fairly similar between the observed and simulated time series. Again the OR experiment appears generally more realistic. The higher-order statistics, such as the skewness (third order) or the kurtosis (fourth order) are also well simulated, except for the only case of the low resolution model in Resistencia. The pressure time series in Resistencia and Ezeiza have kurtosis lesser than 3 whereas the Comodoro Rivadavia time series is sharper than the normal distribution. This feature is accurately reproduced by the various model versions, which means that not only the variability and asymmetry of the distribution, but also its flatness around the mean value, are correctly simulated. This good correspondence of the observed and simulated statistics ensures a good selection of the cases in the composite analysis. We may also note that, again, the OR version with enhanced 
TABLE 1. Average value (AVG), $t$ absolute minimum and maximum (MIN, MAX), the variance $\left(\mathrm{S}^{2}\right)$, standard deviation (S), standard error (SE), skewness (SK), and kurtosis $(K)$ of the observed pressure time series (OBS) and those simulated experiments CO, LR, and OR (a) at Resistencia (Resis.), (b) Ezeiza (Eze.), and (c) Comodoro Rivadavia (CRV).

\begin{tabular}{lrrrrrrrrr}
\hline \hline & AVG & MIN & MAX & $S^{2}$ & $S$ & SE & SK & $K$ \\
\hline (a) Resis. & & & & & & & & & \\
OBS & 1010.3 & 986.5 & 1028.5 & 46.6 & 6.8 & 0.32 & -0.14 & -0.11 \\
CO & 1019.0 & 998.3 & 1035.6 & 35.9 & 6.0 & 0.28 & -0.12 & 0.09 \\
BR & 1019.1 & 1004.2 & 1034.4 & 26.3 & 5.1 & 0.24 & -0.22 & -0.04 \\
OR & 1019.7 & 1001.3 & 1038.7 & 39.5 & 6.3 & 0.29 & -0.21 & -0.13 \\
(b) Eze. & & & & & & & & \\
OBS & 1016.3 & 991.2 & 1034.0 & 56.1 & 7.5 & 0.35 & -0.20 & -0.06 \\
CO & 1018.3 & 991.0 & 1034.9 & 50.5 & 7.1 & 0.33 & -0.28 & 0.25 \\
BR & 1018.8 & 996.6 & 1039.3 & 62.1 & 7.9 & 0.37 & -0.07 & -0.31 \\
OR & 1021.7 & 1003.6 & 1041.5 & 55.8 & 7.4 & 0.35 & -0.16 & -0.06 \\
(c) CRV & & & & & & & & & \\
OBS & 1005.6 & 975.3 & 1030.4 & 122.3 & 11.0 & 0.51 & -0.22 & -0.44 \\
CO & 1008.2 & 978.6 & 1038.7 & 145.2 & 12.2 & 0.56 & -0.06 & -0.50 \\
BR & 1005.3 & 979.6 & 1039.2 & 121.6 & 11.0 & 0.52 & -0.35 & -0.01 \\
OR & 1013.8 & 983.1 & 1040.3 & 129.3 & 11.3 & 0.54 & -0.21 & -0.36 \\
\hline
\end{tabular}

orography gives better quantitative results for the second- and third-order statistic.

The statistical study of the time series, as we wish to study transient evolutions, must also include some measure of the "memory" of the system, as given by the autocorrelation function. Table 2 gives the number of significative time lags (in days) which were found to correspond to a statistically significant correlation. The analysis is again done for both observed and simulated time series. This statistically significant lag number, or memory, tends to increase slightly with latitude. The difference between the model and the simulations never exceeds two days. The memory of the LR simulation is somewhat smaller, while that of the OR simulation is slightly larger than observed.

\section{Mean meteorological situations associated with the occurrence of pressure minima and maxima in the aerological stations}

The two objectives of this section are, first, to give further insight into the meteorological situations associated with the selected high and low pressure systems, and then test the model's ability to reproduce them. We use composite maps of the geopotential fields associated with a maximum or minimum in the pressure at a given station. The corresponding transient evolution will be analyzed in the next section.

TABLE 2. Number of significant lags in the autocorrelation analysis of the pressure time series, for the observations (OBS) and the three simulations CO, LR, and OR, at the three aerological stations. The length of a lag is 1 day.

\begin{tabular}{lcccc}
\hline \hline & OBS & CO & BR & OR \\
\hline Resistencia & 3 & 2 & 2 & 5 \\
Ezeiza & 3 & 4 & 2 & 5 \\
Comodoro Rivadavia & 4 & 5 & 5 & 6 \\
\hline
\end{tabular}

a. Low pressure cases

Composite maps of ECMWF analyses of 500- and 1000-hPa surfaces and 500-1000-hPa thickness, over the cases of low pressure occurrence in the three stations, are shown in Fig. 7. The 500-1000-hPa thickness provides an indication of the thermal contrasts in the lower troposphere.

The 1000-hPa geopotential field shows, for the three stations, the displacement of a trough over the southern part of the continent connected to a cold front passage. In particular, one can notice the presence of the NWAD, which appears more clearly when the systems are closer to Resistencia station. The NWAD appears episodically in winter and its strongest manifestation occurs just before the arrival of a cold front (Lichtenstein 1989). This is caused by the baroclinicity associated with the frontal systems, which intensifies the westerlies in the upper troposphere and increases the orographic effect. Moreover, the warm advection that precedes the front diminishes the pressure, and also contributes to the NWAD intensity. This NWAD plays an important role in determining the precipitation pattern because its intensification brings warm and humid air from the north to middle latitudes, which is then taken up by the frontal systems.

The configuration of the geopotential at $500 \mathrm{hPa}$ also shows the displacement of a cyclonic perturbation at midlatitudes, the inflexion point of the trough being located over the respective stations. The reflection of the perturbation at the 500-hPa level is weak, which shows the shallowness of the selected systems.

Finally the 500-1000-hPa thickness shows a zone of maximum baroclinicity near $35^{\circ} \mathrm{S}$, and a warm area due to the penetration of air from subtropical latitudes, connected to the persistent northerly wind. The Comodoro Rivadavia station composite maps show that the most intense midtropospheric flow and the largest baroclin- 

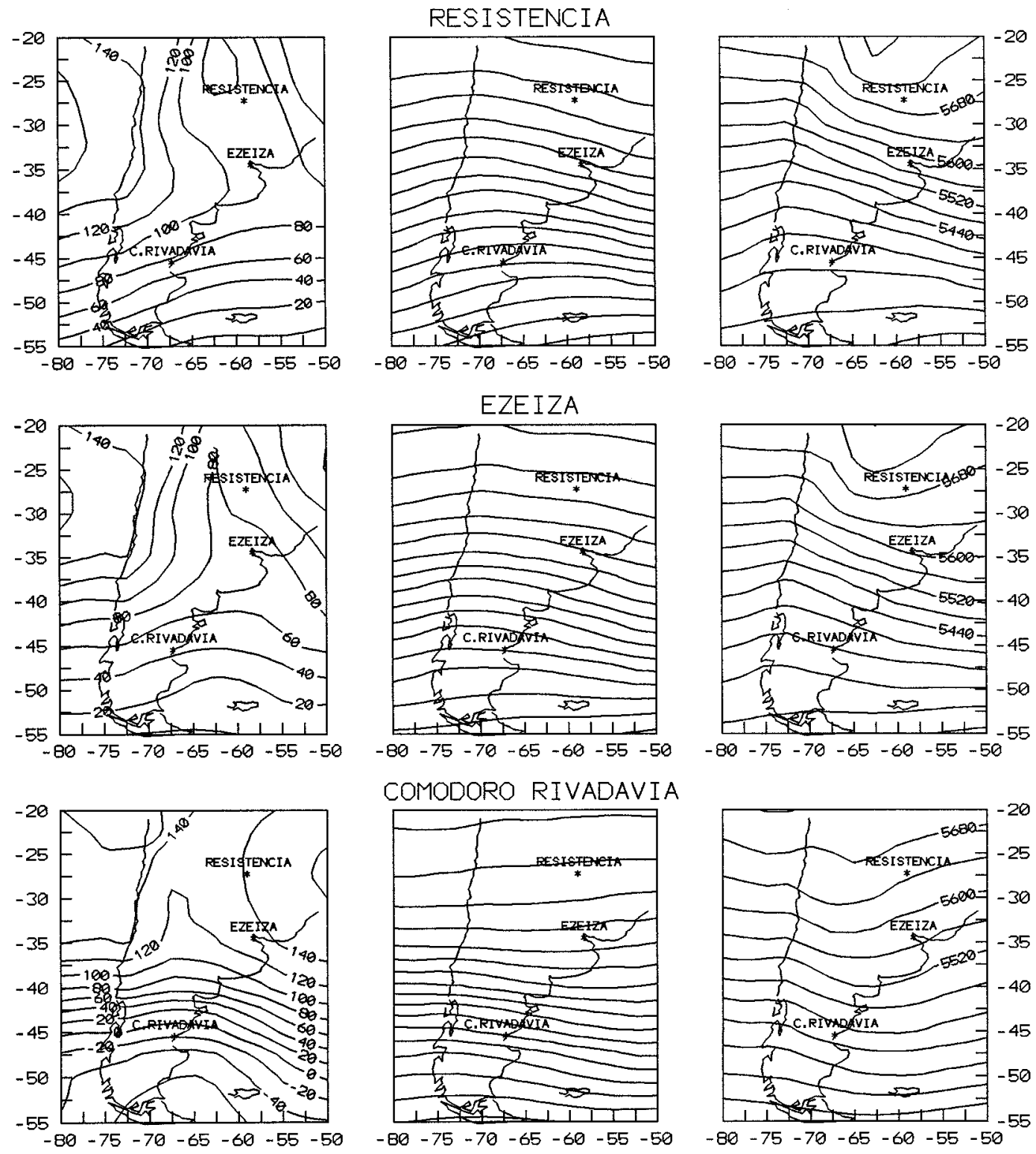

Fig. 7. Mean geopotential height at the levels $1000 \mathrm{hPa}$ (gpm, left panels), $500 \mathrm{hPa}$ (gpm, center), and of the 5001000-hPa geopotential depth (gpm, right panels) associated with the occurrence of minima in Resistencia (upper panels), Ezeiza (center), and Comodoro Rivadavia (lower panels). The analyzed data are analysis from the ECMWF, for winter situations.

icity occurs north of this station. Following usual definitions (Pettersen 1956; Bluestein 1993), this position in latitude indicates that a pressure minimum at the latitude of Comodoro Rivadavia generally corresponds to the passage of a cold occlusion.

We show in Fig. 8 the sea level pressure composite associated, for each model simulation CO, LR, and OR, respectively, with the pressure minima at the three stations. This sea level pressure field was preferred to the equivalent $1000-\mathrm{hPa}$ geopotential height, when analyzing mean situations, because the extrapolation of the models' results to the $1000-\mathrm{hPa}$ level appears numeri- cally less accurate in the model standard output in the presence of strong orography. When analyzing variability patterns we revert to the use of the $1000-\mathrm{hPa}$ height, because all systematic errors then disappear. All model simulations manage to represent the general features of the circulation described above. The analysis of the 500-hPa geopotential height and the 500-1000$\mathrm{hPa}$ thickness (not shown here for the sake of brevity) help us to confirm that the cyclonic perturbations shown in Fig. 8 correspond to the displacement of cold fronts in Resistencia and Ezeiza, and to the passage of cold occlusions over Comodoro Rivadavia. In particular, the 

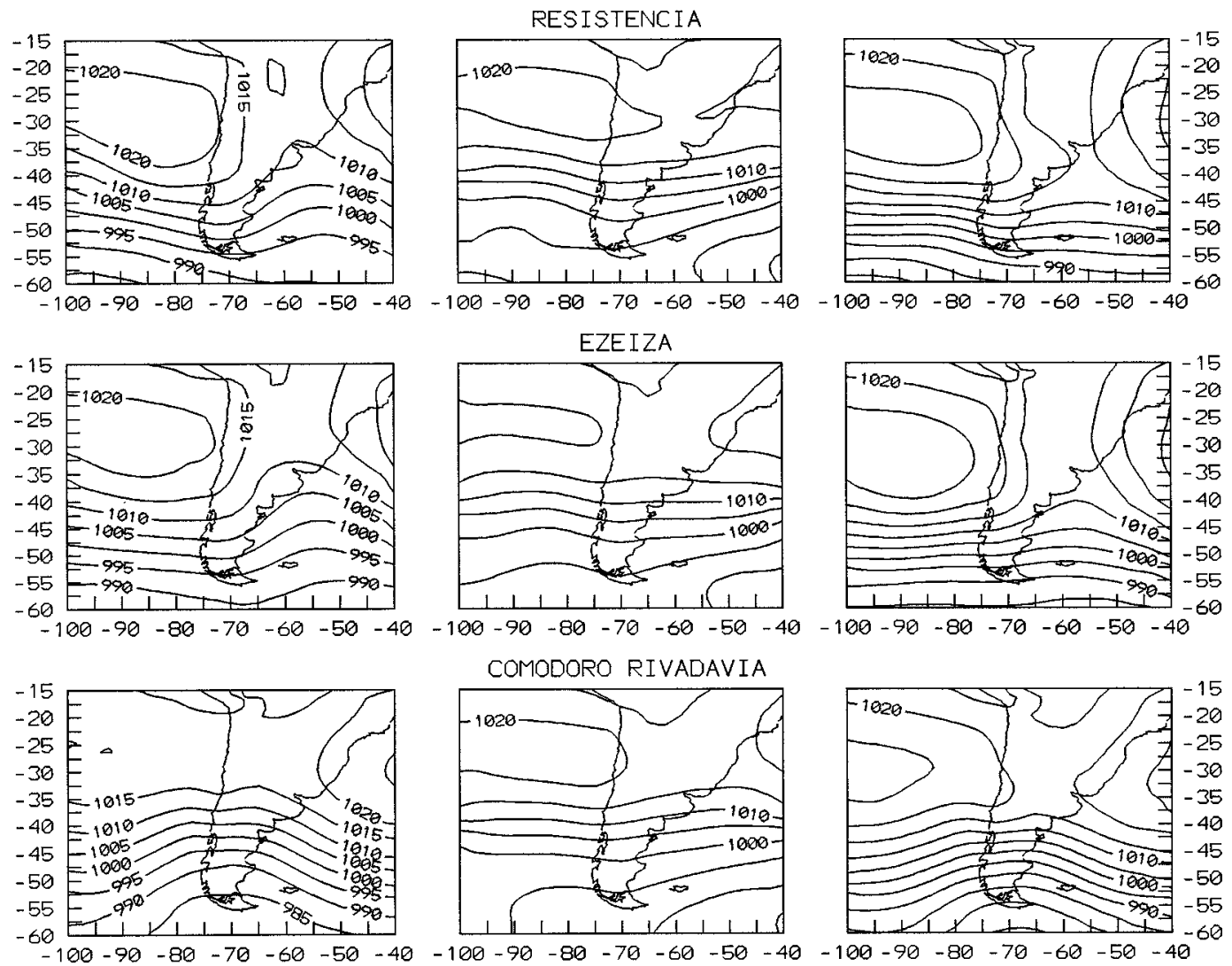

FIG. 8. Mean sea level pressure associated with the occurrence of a minimum in Resistencia (upper panels), Ezeiza (center), and Comodoro Rivadavia (lower panels) for, respectively, the experiments: CO (right panels), (b) LR (center), and OR (left panels).

control simulation (CO simulation, left panels of Fig. 8) simulates correctly the NWAD, whose intensity is, as observed, comparatively larger when the perturbations establish at lower latitudes, as the choice of our three aerological stations allows us to document. However the cyclonic curvature at midlatitudes is slightly displaced toward the east, and overestimated, compared to the ECMWF analysis. The location of the anticyclones is also essentially correct, but not their intensity, at least in the Comodoro Rivadavia case. The westerly flow at midlatitudes is also slightly stronger than observed at midlatitudes. In contrast, the low-resolution model (LR simulation, central panels of Fig. 8) presents a very weak curvature so that the pressure systems are hardly apparent. The anticyclones are displaced too much to the north, and their intensity, unlike in Fig. 7, varies little in relation with the location of the systems. Finally the experiment with enhanced orography (OR, right panels of Fig. 8) is the most similar to the observations, both for the location and intensity of pressure patterns. The NWAD is not clearly evident, but a temporal analysis not presented here shows that this simulation is the one that reproduces most accurately the intermittent life cycle of the depression. The position of the anticyclones, the relation between their intensity and the location of the frontal systems, is also correct. In spite of this, the pressure latitudinal gradients, and hence the zonal flow, are overestimated.

\section{b. High pressure cases}

The mean situation associated with the high pressure winter cases at the three stations is displayed in Fig. 9. ECMWF analysis shows that the selected cases are characterized by very large transient anticyclones that follow the route of the cold fronts. These systems present a strong thermal structure, revealed by their small influence on the midtroposphere $(500 \mathrm{mb})$ fields, and, on the contrary, their large impact on the 500-1000-hPa thickness. The pressure maxima in Resistencia are associated, in particular, with anticyclones that displace themselves south of $25^{\circ} \mathrm{S}$, whereas the systems connected to pressure maxima in Comodoro Rivadavia are generally north of this station. This is why, on the average, the pressure maxima in Ezeiza are the highest ones. We can also note that the high pressure systems leeward of the Andes are associated with windward trough systems $\left(71^{\circ} \mathrm{W}\right)$, which episodically cause severe pollution over Santiago de Chile $\left(33^{\circ} \mathrm{S}, 71^{\circ} \mathrm{W}\right)$ (Rutland 1983). The 500 -hPa field shows again that the wave inflexion points 

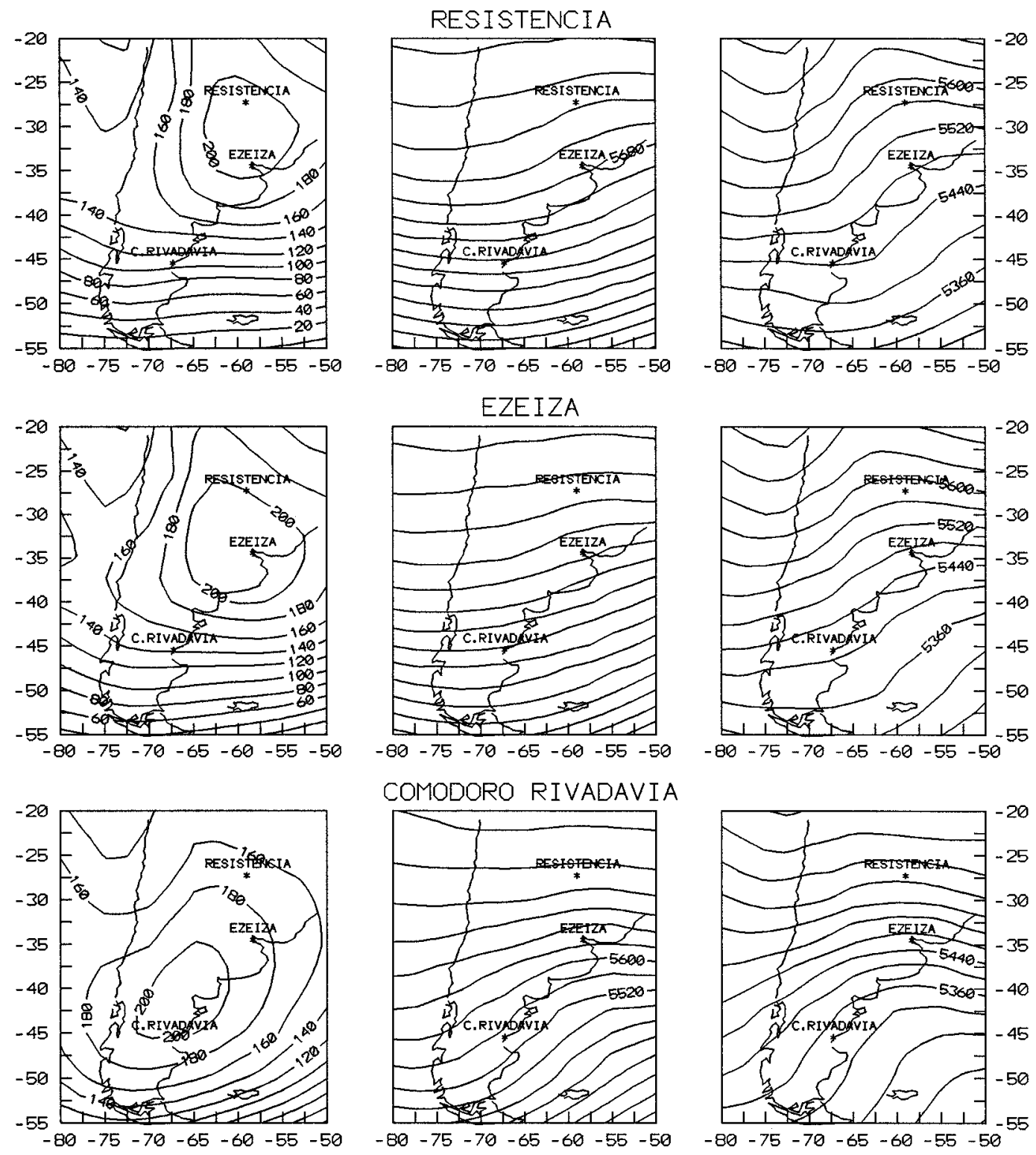

FIG. 9. As in Fig. 7 but for maximum pressure cases.

are located above the three stations. In Comodoro Rivadavia, the ridge is marked by a slight convergence, which tends to increase the anticyclonic vorticity (Petterssen 1956). The 500-1000-hPa thickness reveals that the baroclinicity is more concentrated in the Comodoro Rivadavia map, and that it diminishes when the perturbations are located farther north. The cold outbreak south of $35^{\circ} \mathrm{S}$ is also more intense for the composite pattern associated with the Comodoro Rivadavia systems. In the case of Ezeiza and, especially, Resistencia, a warm-air area appears in the western part of Argentina due to the advection from the north on the western side of the anticyclone, and to the subsidence generated by the high pressure ridge in the midtroposphere.

Figure 10 shows composite SLP maps from the dif- ferent model versions. Again the model appears able to simulate the general feature of the composite situations linked to the occurrence of high pressure events in the three stations.

The composite 500-hPa and 500-1000-hPa thickness maps (not shown here) also reveal a thermal and dynamical structure very similar to that obtained from the ECMWF analysis. The control simulations ( $\mathrm{CO}$, left panels of Fig. 10) reproduce the anticyclonic patterns with both the correct location and amplitude, except in the Comodoro Rivadavia map where the systems are slightly too weak. The relative minimum of pressure located upwind, although slightly underestimated, reveals the impact of the orography. The zonal flow is somewhat too strong, as is also the anticyclonic cur- 

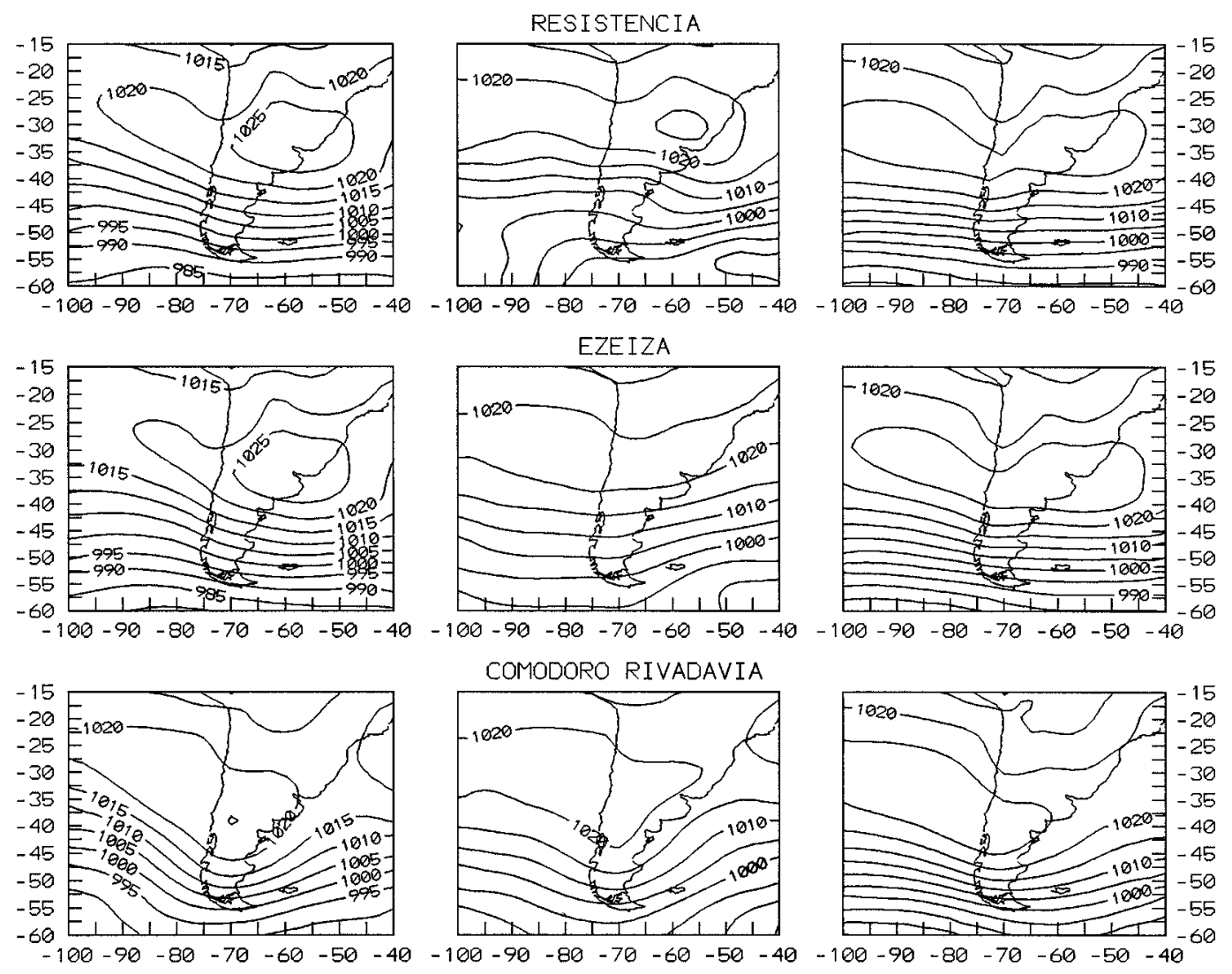

FIG. 10. As Fig. 8 but for maximum pressure cases.

vature, especially for the most southern perturbations. The use of a lower resolution (LR, central panels of Fig. 10) does not diminish the realism of the simulations as much as it does in the low pressure composites. The placement of the anticyclones remains realistic, with a slightly poorer performance in the case of the Ezeiza composite, where the model hardly distinguishes the transient perturbation from the tropical anticyclones belt. The use of enhanced orography (OR, right panels of Fig. 10) does not improve the representation of the anticyclonic patterns. These patterns remain correctly located, but their structure is slightly less delineated. In spite of this quality some features are better represented in the OR simulation: location and intensity of the subtropical anticyclone over the Pacific and better manifestation of the low pressure upwind of the Andes. The westerly winds also remain overestimated, but their anticyclonic curvature is more realistic.

\section{The relevance of the composite approach: A statistical study}

The analysis of transient perturbations through a composite approach is attractive, as mentioned above, because the analysis of the results is rather straightforward; but the validity of the approach is clearly a decreasing function of the scatter among the various situations averaged in the composite maps. To this end we have analyzed the standard deviation of all the fields contributing to the composite maps shown in section 6 . This standard deviation is in each case computed of an ensemble of 60 samples (5 cases for 4 times over 3 months).

We present here the case of the winter pressure minima in the three stations, displayed in Fig. 11. When computing the standard deviation, the reference is the average JJA situation. The dispersion of the $1000-\mathrm{hPa}$ height (left panels of Fig. 11) increases with latitude to reach a maximum at about $60^{\circ} \mathrm{S}$, due to the major activity of the transient systems (Carleton 1979; Sturman 1979). The effect of the orography is clearly revealed by the increase of the variability downwind from the Andes, which reflects a stronger baroclinic activity where the flow is being deflected by the mountains. The field selected by the composite procedure is also characterized by a minimum in the variability at the location of the three aerological stations. The selection procedure therefore chooses situations with a variability lower than the natural variability because they enclose only a particular kind of transients (low pressure systems). This feature is also apparent in the midtroposphere variability field (central panels of Fig. 11). 

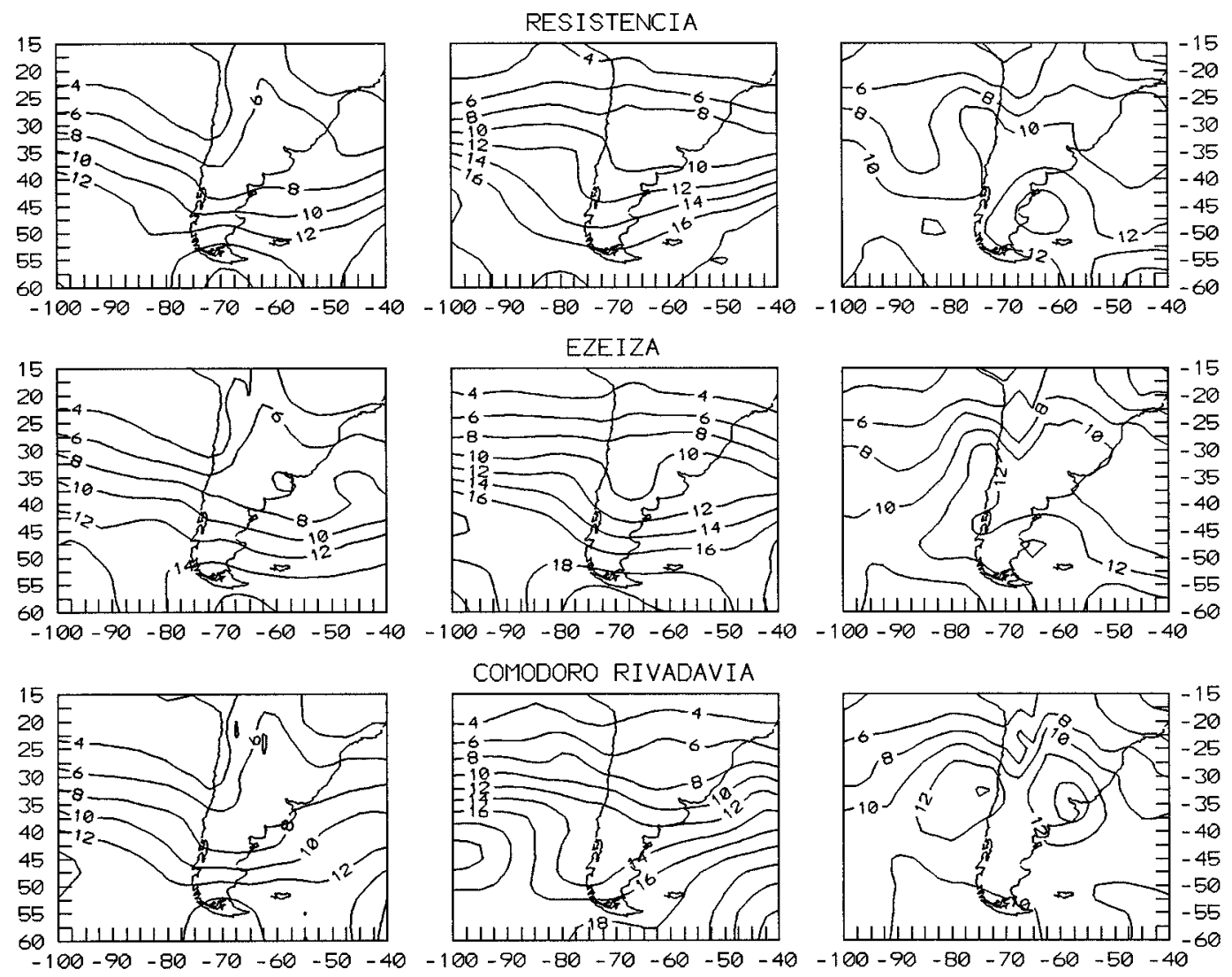

FIG. 11. Mean standard deviation of the geopotential height at the 1000-hPa (gpm, left panels), 500-hPa levels (gpm, center), and the 500-1000-hPa geopotential depth (gpm, right panels) associated with the occurrence of a minimum in Resistencia (upper panels), Ezeiza (center), and Comodoro Rivadavia (lower panels).

The climatic maps of the thermal variability in the winter midtroposphere show a maximum at $40^{\circ} \mathrm{S}$ (not shown) On the contrary, as shown in Fig. 11 (right panels), the maximum dispersion in the 500-1000-hPa thickness field associated with low pressure occurrence (and strongly correlated with the variability of the temperature at about $700 \mathrm{hPa}$ ) is located $5^{\circ}-10^{\circ}$ farther south than the location of the maximum in total thermal variability in the Resistencia and Ezeiza cases. It occurs $10^{\circ}$ farther north in the Comodoro Rivadavia case. This suggests that the meteorological systems studied in this paper have a relatively stable thermal structure above the respective aerological stations. The largest variability is then the result of the advective processes that occur before or after the passage of the perturbation.

We now turn to the model. Figure 12 shows the standard deviation of the 1000-hPa geopotential associated with low pressure systems in the three stations for the CO (left panels), LR (central panels), and OR (right panel) simulations. In general the variability fields are consistent with those of the observations, with an amplitude realistically larger at midlatitudes. The control experiment is generally slightly more variable than the observed analysis, and shows the role of the Andes through the contrast between both sides of the moun- tains. The LR experiment, if anything, tends to be more realistic in terms of amplitude of the variability, and in spite of the low resolution, the relative minimum of variability over the stations, and the role of the Andes, are clearly shown. Again the OR experiment appears more realistic. If the amplitude of the variability is slightly overestimated, the simulated patterns more closely match the observed ones. The effect of the orography is reproduced with good accuracy, which is again proof of the crucial role played by the Andes in the development of baroclinic instability over South America downwind from the mountains barrier. Moreover, the relative minimum of dispersion over the three aerological stations is more clearly shown in OR than in the other simulations.

The variability between the high pressure cases (not shown here) shows structures roughly similar to those in Figs. 11 and 12, with values about 10\% smaller. This shows that high pressure systems have a more stable dynamical and thermal structure compared to cyclonic transients associated with low pressure occurrence.

\section{Propagation of the perturbations: A test case}

Figure 13 displays the 1000- and 500-hPa geopotential anomalies associated to wintertime low pressure sys- 

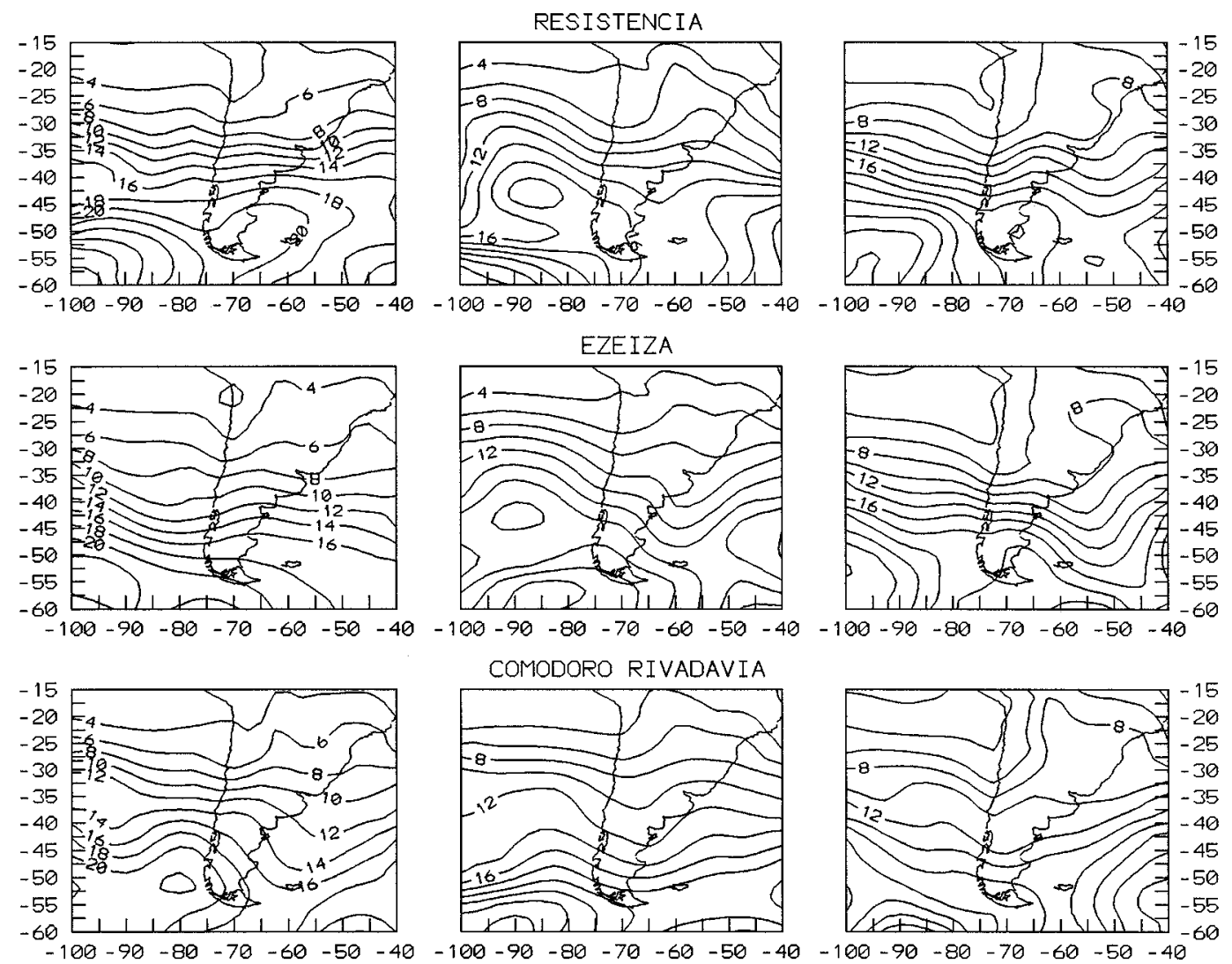

FIG. 12. Mean standard deviation of the 1000-hPa geopotential distributions associated with the occurrence of a minimum in Resistencia (upper panels), Ezeiza (center), and Comodoro Rivadavia (lower panels) for, respectively, the experiments: CO (right panels), (b) LR (center), and OR (left panels).

tems at the Ezeiza station, for the day of the occurrence (central column), the day before the occurrence (left), and the day following the occurrence (right), as computed by Seluchi (1993). The 500-1000-hPa thickness is also given. These situations are linked on the average, as seen before, to cold front passages and serve hereafter as a reference to test the model. As mentioned above, the term anomaly refers here to the difference between the actual situation and the mean JJA climatology. It is a simple manner to isolate and to depict migratory systems movement. On day -1 (left column) we can already note the northern extension of the geopotential anomaly at the east of the Andes, which is then confirmed on day 0 . This feature was also found by Hsu (1987) and Buzzi and Tosi (1989) for the Rocky Mountains. They interpreted it as the result of the dispersion of Rossby wave energy. Gan and Rao (1994) observed the same kind of pattern for the Andes by applying a lag-correlation analysis to the 1977-79 geopotential data from the National Meteorological Center (NMC). The baroclinic nature of the system, and its westward propagation is clearly apparent on the $500-\mathrm{hPa}$ anomaly, which is unaffected by orography. The $500-1000-\mathrm{hPa}$ thickness also reflects the ascending branch upwind of the Andes, with the corresponding subsidence down- wind. A very similar pattern was obtained for high pressure systems (not shown here), the only difference being mainly the sign of the anomalies. The northern extension of positive and negative anomalies provides an easy explanation for the higher geopotential and thermal variability on the lee side of the Andes.

Figure 14 shows the same composite diagram as Fig. 13 but for the control version CO of the LMD GCM. Compared to the ECMWF analysis the structure of the model fields at the lower level appears smoother. The amplitude of the pressure and thermal perturbations is, in contrast, larger than observed. Disturbances, especially at the 500-hPa level, are placed farther north in the CO experiment and the wave fronts show a more apparent southwest-northeast tilt. This latter element may suggest an unrealistically strong meridional momentum transport by the model. However the northern extension of the low pressure patterns is visible on day 0 , and the phase of the systems appears basically correct. The wavelength at the lower and middle troposphere, as computed from the distance between two consecutive centers, are comparable to the ECMWF analysis and we expect the temporal propagation of the systems to be well simulated in the model. Also the large cross-moun- 

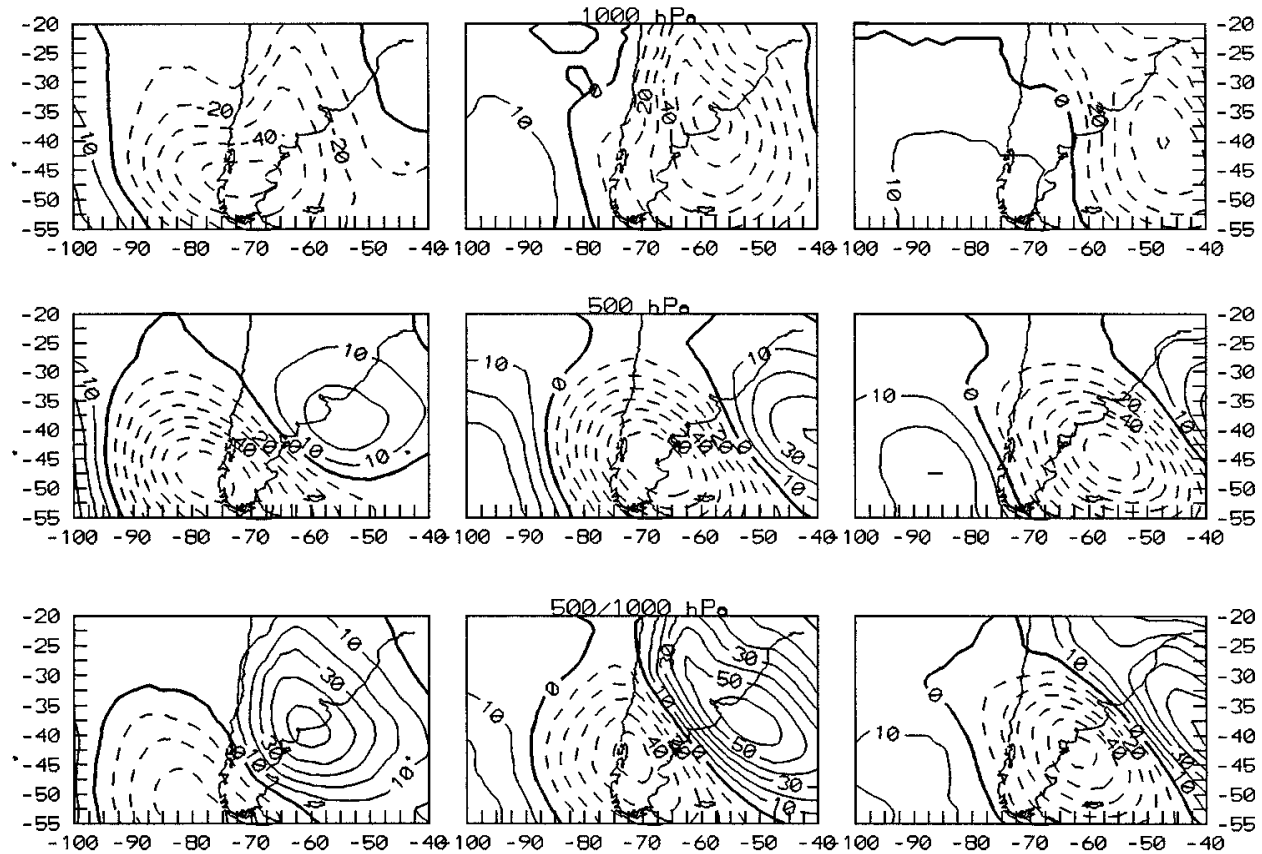

FIG. 13. Anomalies of the geopotential height, at the levels $1000 \mathrm{hPa}$ (upper panels), $500 \mathrm{hPa}$ (center), and of the 500-1000-hPa geopotential depth (lower panels) associated with the occurrence of minima in Ezeiza, on the day prior to the occurrence (left panels), on the day of the occurrence (center), and on the day following the occurrence of the mean (right panels). The analyzed data are the ECMWF analysis, for the winter season.
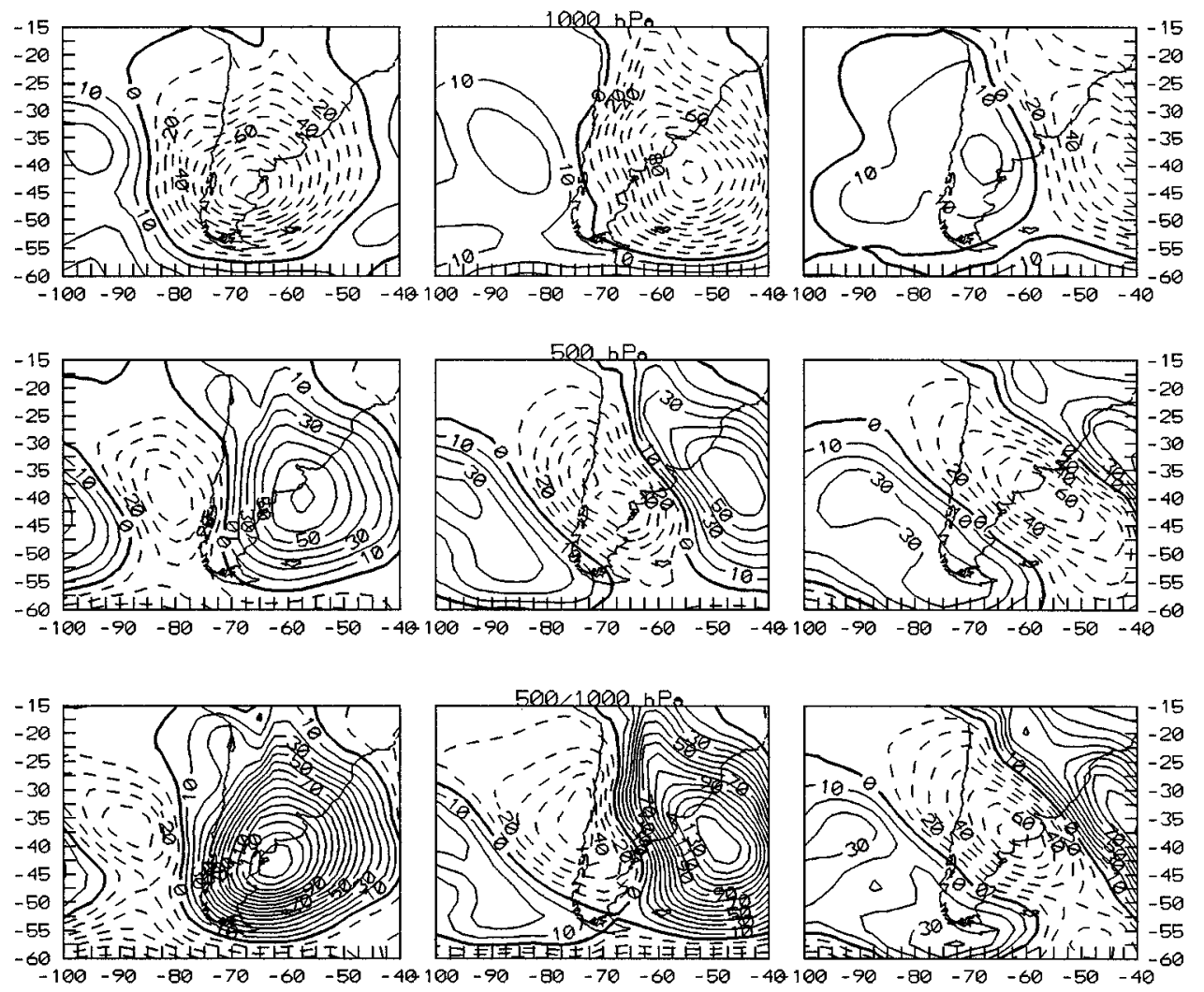

Fig. 14. As Fig. 13 but for experiment CO. 

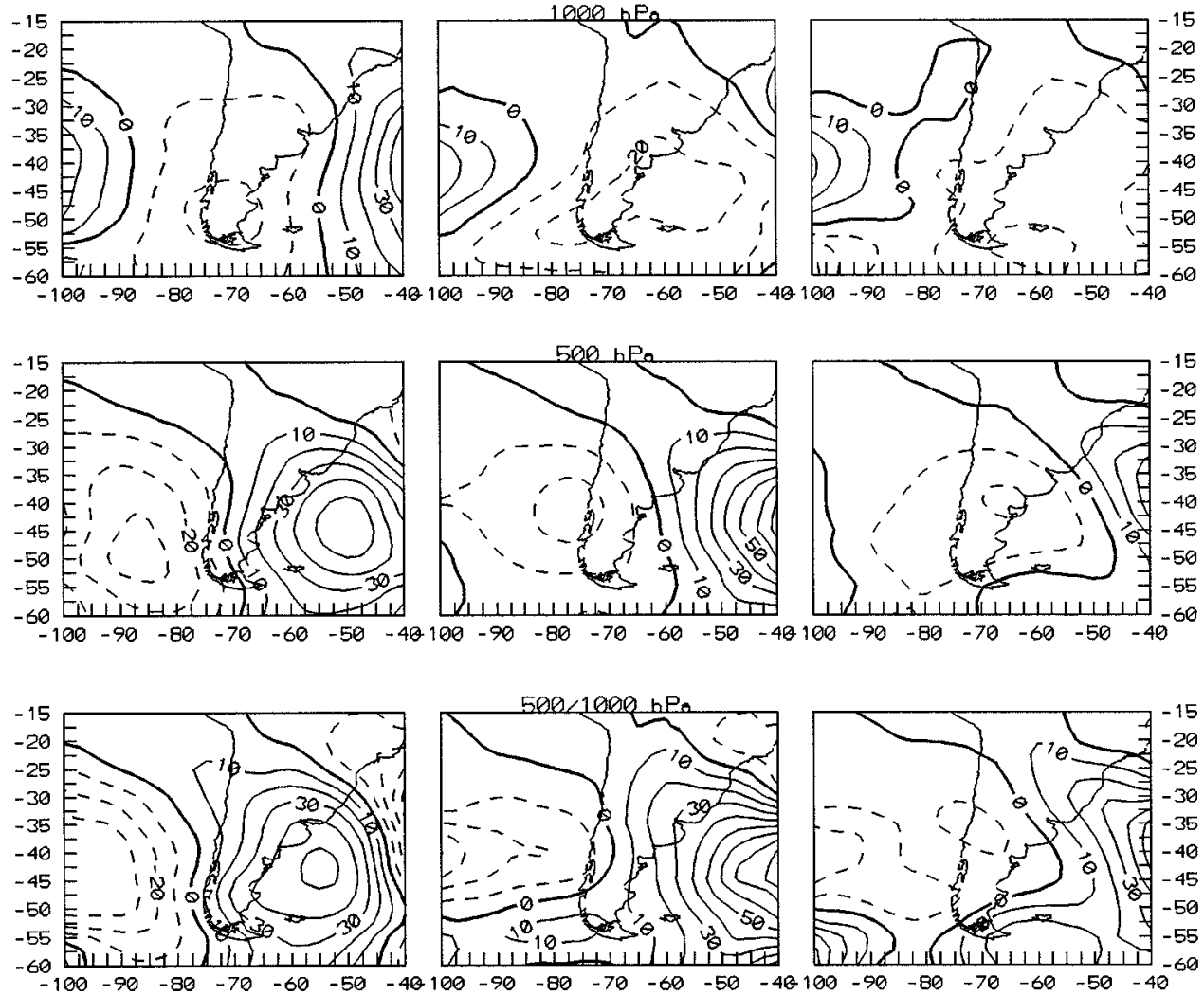

FIG. 15. As Fig. 13 but for experiment LR.

tain gradient in the 500-1000-hPa thickness is correctly simulated.

Figure 15 shows the same geopotential anomalies but for the experiment LR, which has a lower horizontal resolution. The amplitude of the migratory systems is now very weak compared to all higher-resolution experiments, although again the location of the systems is basically correct. We can also note that the length of the waves is larger, and, as a result, their propagation speed is clearly undervalued. This is probably due to the poor resolution, which cannot appropriately resolve short wave baroclinic eddies. However even in this case a slight northward propagation of the surface perturbation can be noted.

Figure 16 represents the same diagnostics as Figs. 13, 14 , and 15 , but for the OR experiment in which the orography of the Andes is enhanced by $1000 \mathrm{~m}$ in its central part. We can first verify that the location, structure, northern spreading, and time evolution of the perturbation is most similar to the ECMWF analysis. In addition, the amplitude of these migratory perturbations is smaller than the one in the $\mathrm{CO}$ case, a feature that appears more realistic. The results of the experiment OR also tend to confirm that the performance of LR is not due to the smoother orography, but more probably to an inadequate representation of the baroclinic sys- tems, which are no longer resolved with sufficient accuracy.

Finally we may sum up briefly the main differences that distinguish the winter cases (shown here) from the summer cases (not shown here). During summertime the atmospheric circulation in the Southern Hemisphere is highly zonal and transitory waves are restricted to the higher latitudes (Streten and Troup 1973). The orographic influence on these transient systems is less important because of the smaller elevation of the Andes at the southern extremity of the continent. In particular, cold-frontal systems cannot reach subtropical latitudes as they usually stall over $35^{\circ}-30^{\circ} \mathrm{S}$ and return later to the south as warm fronts. On the other hand, transient anticyclones have a very zonal track during this season because they avoid the hot continental soil and migrate quickly to oceanic positions. During this season the results obtained by the different experiments show only slight discrepancies, and in general all the outputs of the model can reproduce the essential characteristics of the summer transient systems. Perhaps the most conspicuous orograhic feature of the summer circulation in the upper troposphere is the appearance of the PeruvianBolivian Anticyclone (Kreuels et al. 1975; Silva Días et al. 1983; Kleeman 1989), which is due to the latent heat release induced by the warm and wet easterlies that 

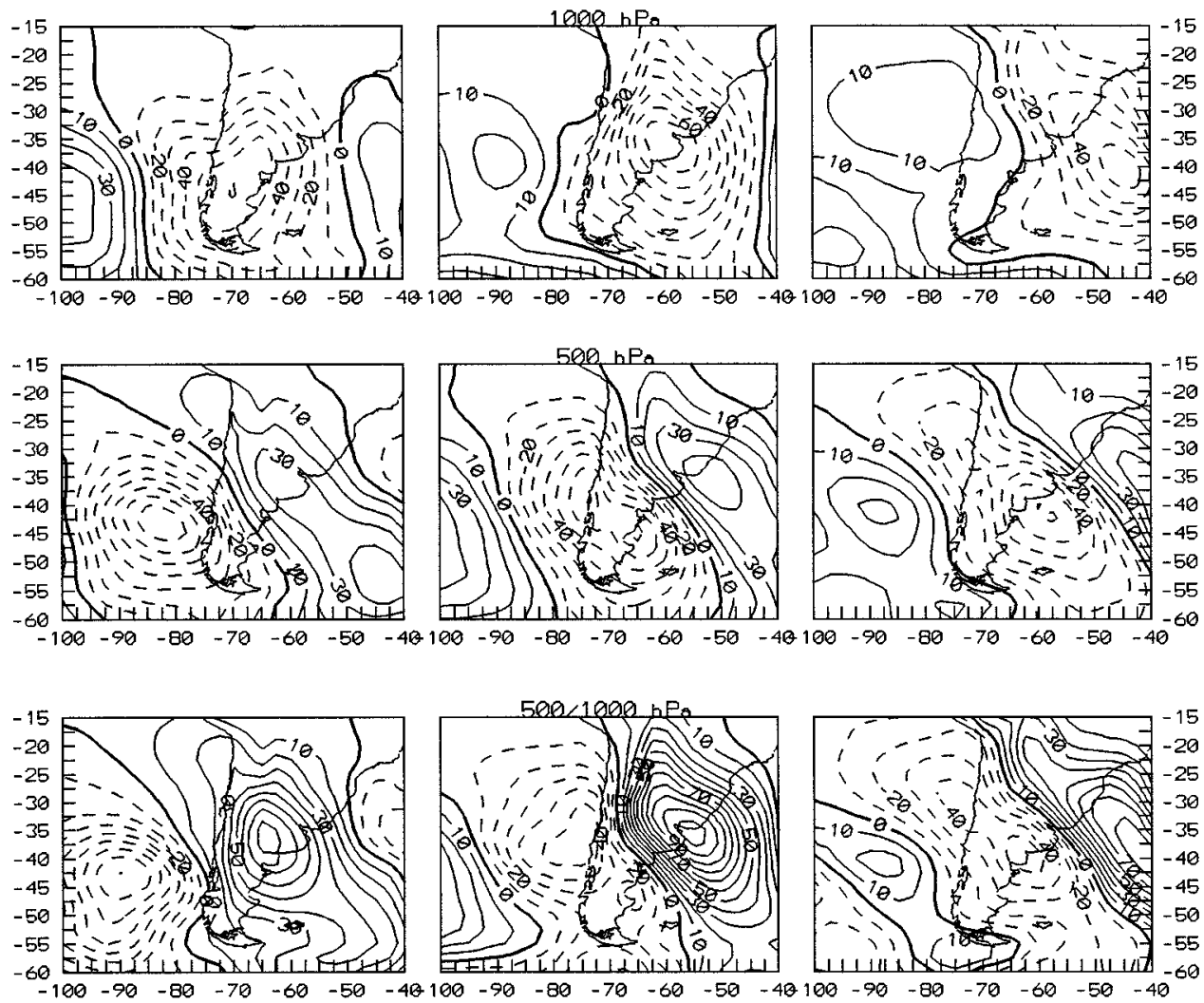

FIG. 16. As Fig. 13 but for experiment OR.

run against the Andes (Gutman and Schwerdtfeger 1965; Figueroa et al. 1996). This particularity is well simulated by all the experiments, although the anticyclone is generally placed $5^{\circ}$ farther south of its actual climatic position.

\section{Conclusions}

We have analyzed the simulation of the transient systems that cross the Andes at extratropical latitudes, using a general circulation model prepared for climate studies. Climate simulations are perhaps those for which the role of the Andes on the synoptic and regional circulation is the most conspicuous. These effects are also particularly difficult to reproduce with a GCM because of the narrowness and sharpness of the mountains.

The model has first been shown to simulate well the mean dynamical patterns present over South America, in spite of its deficiency in simulating the precipitation fields, a feature that may result from an oversimplified water vapor transport scheme. Two parallel simulations meant to investigate the role of model resolution and model orography have also been carried out. The use of a lower-resolution model diminishes the intensity of the stationary weather patterns, but does not affect too strongly their location. The use of an enhanced orography, more realistic than the box-averaged orography, improves many features of the mean circulation.
The transient perturbations have been studied by using local statistics at three aerological stations, which show a very good behavior of the model. Again the simulation with enhanced orography performed better, and the lower-resolution simulation slightly poorer. These results and this ranking among the three simulations are confirmed by the results of a composite analysis based on the occurrence of sea level pressure minima or maxima at three aerological stations.

Finally we use the same composite method to analyze the impact of the Andes on the transient systems that propagate at different latitudes. The model appears able to represent the structure of those systems with a sufficient degree of realism. Once more going from the low-resolution case to the higher-resolution simulations, the model becomes more realistic not only in the location but also the amplitude of those migratory systems. The strong influence of the orography on these pressure systems is felt in all their characteristics (location, propagation, amplitude), and the model appears in all cases more realistic if we increase the altitude.

On the whole, the results show that large-scale models at the resolution used for present climate simulations are able to reproduce with good accuracy the interaction of the continental-scale perturbations with a large mountain barrier as the Andes. The poorer performance of the lower-resolution model, which cannot be explained 
by the smoother orography, suggests that the resolution of about $3.5^{\circ}$ used in the control case must be close to the minimum resolution necessary to adequately resolve the baroclinic waves and their displacement. The better performance of the enhanced orography model shows that the role of the Andes on the circulation can be simulated correctly, either crudely, as in the present study, or through more sophisticated subgrid-scale representations of the orography. In any case the realism of the model appears sufficient to consider its use for regional climate sensitivity experiments. In particular, the association of a good simulation of the large-scale dynamical fields, with an obvious difficulty in adequately representing the hydrological cycle, makes it very tempting to use a mesoscale model embedded in the large-scale climate model.

Acknowledgments. This work has been supported by the Commission of the European Communities under Contracts CT90-0341 and CT94-0111. The authors acknowledge gratefully the role of Pr. Lichtenstein in the initiation of those studies, as well as the help and advice of Z. X. Li, I. Musat, and B. Weare.

\section{REFERENCES}

Bluestein, H. B., 1993: Synoptic-Dynamic Meteorology in Midlatitudes. Vol II: Observations and Theory of Weather Systems. Oxford University Press, 594 pp.

Boer, G. J., N. A. McFarlan, R. Laprise, J. D. Henderson, and J. P. Blanchet, 1984: The Canadian Climate Center spectral atmospheric general circulation model. Atmos.-Ocean, 22, 397-429.

Bunker, A. F., 1976: Computation of surface energy flux and annual air-sea interaction of cycles of the North Atlantic Ocean. Mon. Wea. Rev., 104, 1122-1140.

Buzzi, A., and E. Tosi, 1989: Statistical behaviors of transient eddies near mountains and implications from theories of lee cyclogenesis. J. Atmos. Sci., 46, 1233-1249.

Carleton, A. M., 1979: A synoptic climatology of satellite-observed extra tropical cyclone activity for the S.H. winter. Arch. Meteor. Geophys. Biokl., B27, 265-279.

Figueroa, N. F., P. Satyamurty, and P. L. Silva Diaz, 1996: Simulations of the summer circulation over the South American region with an eta coordinate model, J. Atmos. Sci., 52, 1573-1584.

Fouquart, Y., and B. Bonnel, 1980: Computations of solar heating of the Earth's atmosphere: A new parameterization. Beitr. Phys. Atmos., 53, 35-62.

Gan, M. A., and V. B. Rao, 1994: The influence of the Andes Cordillera on transient disturbances. Mon. Wea. Rev., 122, 11411157.

Gutman, G. J., and W. Schwerdtfeger, 1965: The role of latent heat for the development of a high pressure system on the subtropical Andes in summer. Meteor. Rundsch., 18, 69-75.

Harzallah, A., and R. Sadourny, 1995: Internal versus sea surfacetemperature-forced atmospheric variability as simulated by an atmospheric general circulation model. J. Climate, 8, 474-495.

Hoffmann, J. A., 1975: Atlas Climatico de Sudamerica (Climatic Atlas of South America). WMO-UNESCO, Budapest, Hungary.

Hsu, H. H., 1987: Propagation of low-level circulation features in the vicinity of mountain ranges. Mon. Wea. Rev., 115, 18641892.
Jenne, R., H. Crutcher, H. van Loon, and J. Taljaard, 1974: A selected climatology of the Southern Hemisphere: Computer methods and data availability. Tech. Note NCAR-TN/STR-92, 44-49.

Kleeman, R., 1989: A modeling study of the effect of the Andes on the summertime circulation of tropical South America. J. Atmos. Sci., 46, 3344-3362.

Kreuels, R., K. Fraedrich, and E. Ruprecht, 1975: An aerological climatology of South America. Meteor. Rundsch., 28, 17-24.

Le Treut, H., Z. X. Li, and M. Forichon., 1994: Sensitivity of the LMD general circulation model to greenhouse forcing associated with two different cloud water parameterizations. J. Climate, 7, $1827-1841$

Legates, D. R., and C. J. Willmott, 1990: Mean seasonal and spatial variability in gauge-corrected global precipitation. Int. J. Climatol., 10, 111-127.

Lichtenstein, E. R., 1989: Some influences of the Andes Cordillera on the synoptic scale circulation. Preprints, Third Int. Conf. on the Southern Hemisphere Meteorology and Oceanography, Buenos Aires, Argentina, Amer. Meteor. Soc., 146-148.

Madden, R., and P. Julian, 1972: Further evidence of global-scale 5day pressure waves. J. Atmos. Sci., 29, 1464-1469.

Michaud, R., 1990: Extended memory of the initial conditions in long-range forecasts of the January 1983 atmospheric circulation. J. Climate, 3, 461-482.

Miller, M. J., A. C. M. Beljaars, and T. N. Palmer, 1992: The sensitivity of the ECMWF model to the parameterization of evaporation from the tropical oceans. J. Climate, 5, 418-434.

Morcrette, J. J., 1990: Impact of changes to the radiation transfer parameterizations plus cloud optical properties in the ECMWF model. Mon. Wea. Rev., 118, 847-873.

Palmer, T. N., G. J. Shutts, and R. Swinbank, 1986: Alleviation of a systematic westerly bias in general circulation and numerical weather prediction models through an orographic wave drag parameterization. Quart. J. Roy. Meteor. Soc., 112, 1101-1084.

Petterssen, S., 1956: Weather Analysis and Forecasting. Vol. 1. McGraw-Hill, 428 pp.

Physick, W. L., 1981: Winter depressions tracks and climatological jet streams in the Southern Hemisphere during the FGGE year. Quart. J. Roy. Meteor. Soc., 107, 883-898.

Polcher, J., and K. Laval, 1994: The impact of African and Amazonian deforestation on tropical climate. J. Hydrol., 155, 389-405.

Rutland, J., 1983: Coastal lows in central Chile. Preprints, First Int. Conf. on Southern Hemisphere Meteorology, Sao Jose dos Campos, Brazil, Amer. Meteor. Soc., 344-346.

Sadourny, R., and K. Laval, 1984: January and July performance of the LMD general circulation model. New Perspectives in Climate Modeling, A. L. Berger and C. Nicolis, Eds., Elsevier, 173-197.

Schwerdtfeger, W., 1976: World Survey of Climatology. Vol. 12. Climates of Central and South America, Elsevier, 532 pp.

Seluchi, M. E., 1993: Estudio del Comportamineto de los Sistemas Sinopticos Migratorios en la Argentina (Study of the synoptic transient systems in Argentina). Ph.D. thesis, Universidad de Buenos-Aires, 243 pp. [Abstract in English available from CIMA Pabellon II, Piso I, Ciudad Universitaria, (1428) Buenos Aires, Argentina.]

Servicio Meteorlógico Nacional, 1960: Atlas Climático de la República Argentina (Climatic Atlas of the Argentinean Republic). Servicio Meteorlógico Nacional (National Meteorological Service of Argentina), $83 \mathrm{pp}$.

Silva Dias, P. L., W. H. Schubert, and M. De Maria, 1983: Largescale response of the tropical atmosphere to transient convection. J. Atmos. Sci., 40, 2689-2707.

Streten, N. A., and A. J. Troup, 1973: A synoptic climatology of satellite-observed cloud vortices over the S.H. Quart. J. Roy. Meteor. Soc., 99, 56-72.

Sturman, A. P., 1979: Aspects of the synoptic climatology of southern South America and the Antarctic peninsula. Weather, 34, $210-$ 223. 